University of Nebraska - Lincoln

DigitalCommons@University of Nebraska - Lincoln

Faculty Publications, Department of Psychology

Psychology, Department of

March 1999

\title{
Rationality in medical treatment decisions: Is there a sunk-cost effect?
}

Brian H. Bornstein

University of Nebraska-Lincoln, bbornstein2@unl.edu

Christine Emler

Earl K. Long Medical Center, Baton Rouge, LA

Gretchen B. Chapman

Rutgers University, New Brunswick, NJ

Follow this and additional works at: https://digitalcommons.unl.edu/psychfacpub

Part of the Psychiatry and Psychology Commons

Bornstein, Brian H.; Emler, Christine; and Chapman, Gretchen B., "Rationality in medical treatment decisions: Is there a sunk-cost effect?" (1999). Faculty Publications, Department of Psychology. 212. https://digitalcommons.unl.edu/psychfacpub/212

This Article is brought to you for free and open access by the Psychology, Department of at DigitalCommons@University of Nebraska - Lincoln. It has been accepted for inclusion in Faculty Publications, Department of Psychology by an authorized administrator of DigitalCommons@University of Nebraska - Lincoln. 


\title{
Rationality in medical treatment decisions: Is there a sunk-cost effect?
}

\author{
Brian H. Bornstein, Louisiana State University, Baton Rouge \\ Christine Emler, Earl K. Long Medical Center, Baton Rouge, LA \\ Gretchen B. Chapman, Rutgers University, New Brunswick, NJ
}

\begin{abstract}
Objective: To assess residents' propensity to display the sunk-cost effect, an irrational decision-making bias, in medical treatment decisions; and to compare residents' and undergraduates' susceptibility to the bias in non-medical, everyday behaviors.

Design: Cross-sectional, in-person survey.

Setting: Louisiana State University, two locations: Medical Center-Baton Rouge and Main Campus-Psychology Department.

Participants: Internal medicine and family practice residents $(N=36$, Mdn age $=27)$ and college undergraduates $(N=$ 40, Mdn age $=20$ ).

Measurements and main results: Residents evaluated medical and non-medical situations that varied the amount of previous investment and whether the present decision maker was the same or different from the person who had made the initial investment. They rated reasons both for continuing the initial decision (e.g., stay with the medication already in use) and for switching to anew alternative (e.g., a different medication). There were two main findings: First, the residents' ratings of whether to continue or switch medical treatments were not influenced by the amount of the initial investment ( $p$ 's $>0.05$ ). Second, residents' reasoning was more normative in medical than in non-medical situations, in which it paralleled that of undergraduates $(p$ 's $<0.05)$.

Conclusions: Medical residents' evaluation of treatment decisions reflected good reasoning, in that they were not influenced by the amount of time and/or money that had already been invested in treating a patient. However, the residents did demonstrate a sunk-cost effect in evaluating non-medical situations. Thus, any advantage in decision making that is conferred by medical training appears to be domain specific.
\end{abstract}

Keywords: Decision making, Biases, Medical education

\section{Introduction}

Sound decision making is a key element of good medicine; thus, decision errors often have clinical importance.
A large body of psychological research has identified a number of decision errors and irrational biases in non- 
medical domains (Baron, 1994). Medical decision making research has sought to uncover some of the parallels between cognitive biases which exist in the non-medical world and in the medical world (Detmer et al., 1978; Elstein et al., 1978; Dawson and Arkes, 1987; Elstein, 1988; for an inventory of medical decision-making biases, see Hershberger et al., 1994). Some of the biases that have been shown to influence medical judgment include the omission bias (Asch et al., 1994), availability bias (Poses and Anthony, 1991), hindsight bias (Arkes et al., 1981; Dawson et al., 1988), a bias to ignore negative evidence when attempting to synthesize information (Mazur and Hickam, 1990), framing effects (McNeil et al., 1984) and outcome bias (Gruppen et al., 1994).

For example, Dawson et al. (1988) asked physicians attending clinicopathologic conferences to estimate the probability of five possible diagnoses. They found that physicians who were informed of the correct diagnosis prior to making their probability estimates ranked it higher in their differential diagnosis than physicians who were not told the correct diagnosis beforehand. This hindsight bias was especially prevalent in less experienced physicians.

One bias which is not represented in the research on medical decision making is the escalation, or sunk cost, effect (Arkes and Blumer, 1985; Brockner, 1992). The sunk cost effect occurs when a decision maker continues to invest resources into a previously selected action or plan even after the plan has proven to be the suboptimal option. For example, Arkes and Blumer (1985) told participants to imagine that they had purchased tickets for two non-refundable ski trips on the same weekend. Even though they were told to assume further that they would enjoy the trip purchased second more, a majority of participants chose the trip purchased first, which had cost them more money. From an economic perspective, choosing the first trip is suboptimal; because the money for both trips has been irretrievably sunk, one ought to choose the trip that would be more enjoyable.

The sunk cost effect has been shown to be a robust cognitive bias in a variety of non-medical domains, such as personal decisions (Arkes and Blumer, 1985; Bornstein and Chapman, 1994), investment decisions in business (Staw, 1976; Garland, 1990), and employee performance evaluations (Bazerman et al., 1982). A number of reasons may underlie decision makers' sunk cost behavior (Bornstein and Chapman, 1994). The most commonly cited reason for why people display /' the sunk cost effect is the desire not to waste already expended resources (Frisch, 1993; Bornstein and Chapman, 1994). Decision makers may feel that if they abandon the original plan, they will be wasting the resources already invested. For example, Arkes and Blumer's subjects may have chosen the more expensive, less enjoyable ski trip because they felt that if they did not take the trip, the money already spent on it would be wasted.

Decision makers may have other rationales for attending to sunk costs as well. One such reason is the desire to teach oneself (or another person) a lesson about how to make better decisions in the future; another possible reason is the desire to appear consistent in one's decisions. Learning a lesson is especially likely to come into play when one person is making a decision on behalf of another (e.g., a parent deciding what a child should do), as opposed to making a decision for oneself (Bornstein and Chapman, 1994). Consistency is an especially important motivation for sunk cost behavior when decision makers are induced to justify their decisions, either publicly or privately (Bobocel and Meyer, 1994). Similarly, decision makers who feel personally responsible for an original plan's consequences are more likely to display sunk-cost behavior than when someone else is responsible (Staw, 1976; Whyte, 1993; Schoorman and Holahan, 1996).

In this study, we explore the role that the sunk cost effect plays in medical decision making. Sunk costs could affect several aspects of medical decision making. For instance, a physician might be more reluctant to change medications after an ineffective trial of a relatively expensive medicine as opposed to an inexpensive medicine. Similarly, a practitioner might be less willing to entertain an alternative diagnosis after spending several hours or days pursuing an apparently inaccurate option than if less time were spent looking at the erroneous diagnosis. In this study, we asked whether resident physicians would display the sunk cost bias by being more likely to recommend continuing with a medical management plan when the initial investment was relatively high (compared to when it was relatively low), even though patient outcomes would be improved by switching to a different management strategy. Because personal responsibility for a failed decision influences one's tendency to continue with it (Schoorman and Holahan, 1996), we also manipulated responsibility by varying whether the current treating physician was the same as or different from the physician who had made the initial treatment decision.

One characteristic of experts across a variety of fields is that they tend to make more accurate and reliable judgments than novices (Ericsson and Smith, 1991), a finding that holds true for increasing levels of medical expertise (Elstein et al., 1978; Patel and Groen, 1991). The expertise literature also indicates that, on the whole, the benefits of expertise are domain specific (Ericsson and Smith, 1991). We therefore compared medical residents' reasoning about medical scenarios to their reasoning about non-medical scenarios. We predicted that the residents would be less subject to the sunk cost fallacy 
when reasoning in their area of expertise than when reasoning out of it.

We predicted that when medical residents did fall prey to the sunk cost fallacy, their motivation would be to appear consistent rather than to avoid wasting resources already invested. Inconsistency in medical treatment might be perceived as an implicit admission of error and thereby indicate low-quality care. The consequences of perceived sub-standard care are potentially severe: malpractice claims, loss of one's patient population or loss of respect from one's peers, all of which could curtail professional advancement. Thus, consistency may be thought of as a good quality, and the need for physicians to see themselves in a good light would lead them to choose the consistency argument over the waste argument when displaying the sunk cost effect. The motivation to appear consistent should therefore be stronger for physicians in the medical domain than it would be in non-medical situations. One reason for this tendency may be the "it didn't happen because of me" phenomenon (Detmer et al., 1978). Detmer et al. found that physicians tended to estimate mortality rates for an entire surgical service to be higher than the physician's own patients' mortality rates. The researchers felt that this might result from "a need to see oneself in a good light and yet not distort one's self-image" (Detmer et al., 1978, p. 682).

We also compared residents' reasoning about nonmedical scenarios to that of undergraduate students. If expertise gained through medical training transfers to areas outside of the resident's medical expertise, then medical residents would be less likely to display the sunk cost bias than undergraduates in non-medical situations. On the other hand, if expertise is completely domain-specific, then residents and undergraduates should show equivalent performance on the non-medical scenarios. Thus, there are two (non-orthogonal) comparisons that are central to the present study: medical residents' decisions in medical versus non-medical situations, and decisions in non-medical situations of resident participants versus undergraduate participants.

\section{Method}

\section{Participants}

The physician participants were 36 residents (26 males, 9 females, and one participant who failed to indicate gender) drawn from one internal medicine and two family practice residency programs in Baton Rouge, Louisiana. The residents ranged in age from 24 to 45 years old $(M=30.23, \mathrm{Mdn}=27)$, and they had been in residency an average of 1.91 years $(\mathrm{Mdn}=2)$. The undergraduate participants were 40 undergraduates ( 9 males and 31 females) from Louisiana State University who were between 18 and 33 years old $(M=20.48, \mathrm{Mdn}=20)$. No monetary incentive was offered in either case; the undergraduates received extra course credit for participating.

\section{Materials and design}

Participants rated decision makers' options in a number of hypothetical scenarios (eight for the residents and four for the undergraduates). It is not uncommon to study decision making by haying participants evaluate others' behavior, in both non-medical (Baron, 1994) and medical domains (Gruppen et al., 1994). The sunk cost literature has failed to find differences in participants' judgments depending on whether they are asked to make decisions themselves or to evaluate another's decisions (Arkes and Blumer, 1985; Bornstein and Chapman, 1994).

The four non-medical scenarios were taken from those used previously by Bornstein and Chapman (1994); see Appendix A for a sample scenario. Four medical scenarios were created such that each scenario presented an ongoing plan and an alternative course of action, as in the non-medical scenarios. For example, in one of the cases (see Appendix A), a patient was started on antisecretory medication because of gastroesophageal reflux. The medication was ineffective and produced drowsiness. The physician must decide whether to maintain the original treatment or discontinue the medication. The medical scenarios were developed by the physician author (ACE) and were reviewed by other physicians for their plausibility.

Two independent variables were varied within each scenario. First, the current plan had been initiated either by the present decision maker herself or by another person (another physician for the medical scenarios). Second, either a high or low level of resources had already been invested in the current plan.

Each non-medical participant read the four nonmedical scenarios, one for each combination of the two variables: (1) identity of the original decision maker (same vs. other); (2) amount of initial investment (high vs. low). Each physician participant read the four nonmedical scenarios as well as the four medical scenarios. The four medical scenarios also had representations of all combinations of the same two within-subject variables as described above. The order of the conditions for both the medical and non-medical scenarios was counterbalanced according to a Latin-square design. The scenarios were presented in one of two different orders. 
Table 1

Mean ratings (with standard deviations) of the three responses for both groups of participants ${ }^{\mathrm{a}}$

\begin{tabular}{llll}
\hline & \multicolumn{2}{l}{ Response } & \\
\cline { 2 - 4 } Participants & normative & waste & consistency \\
\hline Residents & & & \\
Medical scenarios & $8.38(2.34)$ & $2.26(1.84)$ & $2.15(1.90)$ \\
Non-medical scenarios & $6.87(2.25)$ & $3.71(2.76)$ & $2.77(2.26)$ \\
Undergraduates & & & \\
Non-medical scenarios & $6.38(3.46)$ & $4.93(3.20)$ & $4.28(3.08)$ \\
\hline
\end{tabular}

${ }^{a}$ The undergraduates rated only the non-medical scenarios, while the residents rated both types of scenario.

\section{Procedure}

After reading each scenario, participants rated three possible responses using a 10-point scale, with 10 representing "a very good response, the one that [the decision maker] should definitely follow," and 1 representing "a very bad response, that [the decision maker] should definitely not follow" (Bornstein and Chapman, 1994). Participants were allowed to use any number between 1 and 10 as often as they chose. The three possible responses, which were tailored to fit each scenario, were as follows: "normative" - ignore sunk costs and switch to the new, better plan; "waste" - stick with the initial plan so as not to waste the resources already invested; and "consistency" - stick with the initial plan to be consistent with previous behavior. Each response appeared in each ordinal position at least once in the four scenarios of each type (medical and non-medical).
The entire questionnaire took 20-30 min for the physicians to complete ( 8 scenarios) and 10-20 min for the non-medical participants to complete (4 scenarios).

\section{Results \\ Medical residents}

For the residents' data, we first conducted separate ANOVAs on the ratings given to each response (normative, waste and consistency) as a function of three within-subject independent variables: type of scenario (medical or non-medical), identity of original decision maker (same or other) and amount of resources already invested (high or low).

The normative response received the highest mean rating by residents in both the medical and non-medical scenarios (see Table 1). Contrary to our prediction, they did not rate the consistency response higher than the waste response in the medical scenarios. However, the residents did rate both the waste and consistency arguments higher in non-medical as opposed to medical situations, and the normative response was rated higher in medical than in non-medical cases $(F(1,32) \mathrm{s}>6.67, p$ 's $<0.05)$. This pattern indicates that residents are less susceptible to the sunk cost fallacy in medical than in non-medical settings.

The main effect of scenario type on ratings of the consistency response was qualified by an interaction between scenario type and identity of the original decision maker, $F(1,32)=5.61, p<0.05$ (see Fig. 1, left and middle bars). For medical cases, the consistency response was rated higher when the treating physician had initiated the original plan herself than when another physician had; however, for non-medical scenarios, the reverse was true. Thus, the attractiveness of the consistency response in medical

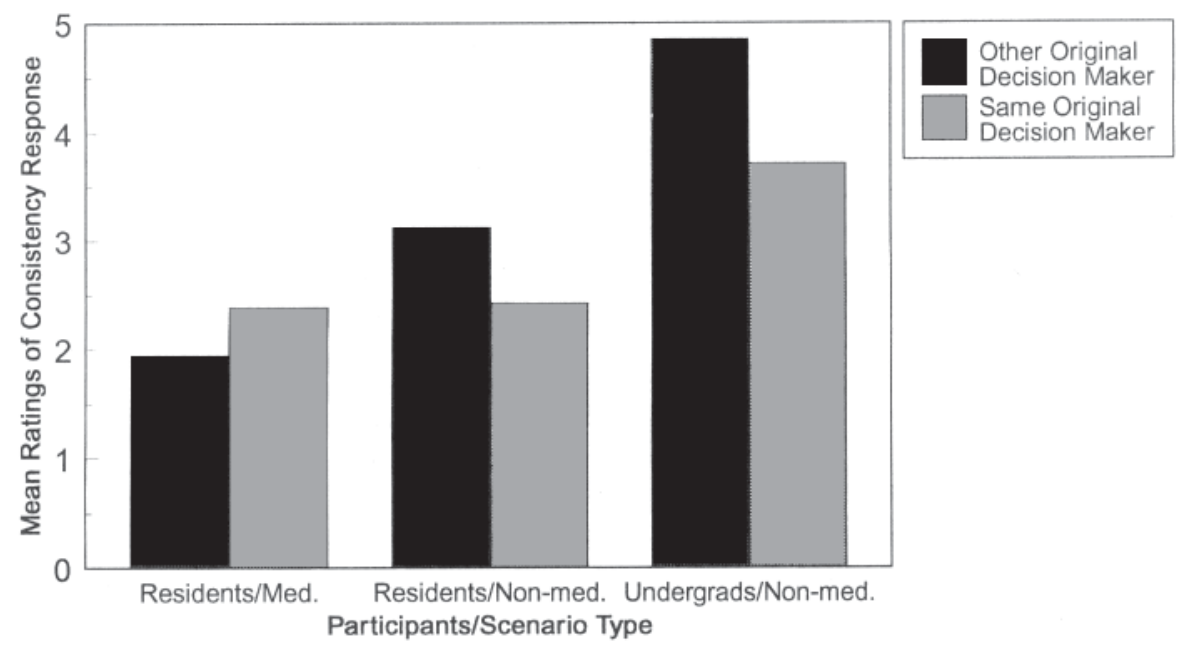

Fig. 1. Mean ratings of the consistency response as a function of identity of the original decision maker (same vs. other) for both residents (medical and non-medical scenarios) and undergraduates (non-medical scenarios only). 
Table 2

Residents, mean ratings (with standard deviations) of the normative response as a function of scenario type, amount of resources invested (low sunk vs. high sunk) and identity of the original decision maker (same vs. other)

\begin{tabular}{lllll}
\hline & \multicolumn{2}{l}{ Scenario type } & & \\
\cline { 2 - 5 } & medical & & non-medical \\
\cline { 2 - 5 } Original decision maker & low sunk & high sunk & low sunk & high sunk \\
\hline Same & $8.39(2.30)$ & $8.17(2.76)$ & $8.44(2.53)$ & $6.47(3.50)$ \\
Other & $8.81(2.00)$ & $8.17(2.26)$ & $5.50(3.39)$ & $7.06(2.86)$ \\
\hline
\end{tabular}

settings appears to be greater when the original decision maker and the present decision maker are the same person than when they are different.

There was no main effect of amount of resources already invested for the waste or consistency arguments, $F(1,32) \mathrm{s}<1.75, p$ 's $>0.19$, nor did level of investment interact with type of scenario or person making the original decision, $F(1,32) \mathrm{s}<3.2, p$ 's $>0.3$. For the consistency response, there was a marginally significant decision maker by amount of resources interaction, $F(1,32)=$ $3.19, p<0.09$. This interaction indicates that consistency was rated higher for high than low resources invested only in the case where the present decision maker had made the original decision.

For the normative response, there was a marginal main effect of resources invested, $F(1,32)=3.43, p<$ 0.08 , indicating that the normative response was rated somewhat lower when a large amount of resources had already been invested. There was no interaction between amount of resources invested and type of scenario, $F(1$, $32)<1, p>0.6$, but there was a 2 -way interaction between amount of resources and person making the original decision, $F(1,32)=7.99, p<0.01$, indicating that the normative response was rated higher for low resources invested only if the original decision had been made by the physician himself. In addition, there was a 3-way interaction among amount of resources, scenario type, and identity of the original decision maker, $F(1,32)=$ $10.95, p<0.005$, indicating that the interaction between amount of resources and identity of the decision maker on ratings of the normative response occurred only for the non-medical scenarios (see Table 2). This pattern suggests further that the predicted interaction between scenario type and amount of resources may occur only when the present decision maker made the initial decision; it fails to occur when someone else made the original decision.

\section{Non-medical scenarios: residents vs. undergraduates}

We next compared the responses of both groups of participants on the non-medical scenarios. The betweensubjects independent variable was participants (residents or undergraduates), and the within-subjects variables were identity of the original decision maker (same or other) and amount of resources already invested (high or low). The dependent variables again were the ratings given to each of the three responses, analyzed in separate univariate ANOVAs.

Undergraduates gave higher responses to the nonnormative responses (waste and consistency) than did residents, $F(1,68) \mathrm{s}>10.24, p$ 's $<0.01$ (see Table 1). This finding is another indication that professional training may improve reasoning. It should be noted, however, that even the undergraduates rated the normative argument higher than both the waste and consistency responses.

Across all participants (both the residents and the undergraduates), the waste response was rated higher and the normative response lower when a high level of resources had already been invested, $F(1,68)$ s $>6.96$, $p$ 's $<0.02$ (see Table 3). Like the waste response, the

Table 3

Mean ratings (with standard deviations) of the non-medical scenarios for both groups of participants, as a function of amount of resources invested (low sunk vs. high sunk)

\begin{tabular}{llll}
\hline & \multicolumn{2}{l}{ Response } & \\
\cline { 2 - 4 } Participants & normative & waste & consistency \\
\hline Residents & & & \\
Low sunk & $6.97(3.32)$ & $3.44(2.62)$ & $2.74(2.32)$ \\
High sunk & $6.76(3.18)$ & $3.99(2.88)$ & $2.81(2.21)$ \\
Undergraduates & & & \\
Low sunk & $7.04(3.41)$ & $4.40(3.06)$ & $4.01(3.12)$ \\
High sunk & $5.72(3.40)$ & $5.48(3.27)$ & $4.55(3.03)$ \\
\hline
\end{tabular}


consistency response was slightly higher when a high level of resources had been invested, though this effect was not statistically significant, $F(1,68)=2.17, p>0.14$. This pattern indicates that participants viewed continuing with the original plan as more attractive when they (or someone else) had already invested many resources into that plan. In other words, both residents and undergraduates demonstrated the sunk cost effect in judging non-medical situations.

To test whether the undergraduates showed more of a sunk cost effect than the medical residents, we examined the interaction between participant group and amount of resources invested. There was no such interaction for the waste or consistency response, $F(1,68) \mathrm{s}<1, p$ 's $>0.3$. This interaction for the normative response was marginally significant, $F(1,68)=3.16, p<0.09$, suggesting a somewhat stronger effect of invested resources for the undergraduates (see Table 3).

Both the undergraduates and the residents rated the consistency argument higher when another decision maker had made the original decision, $F(1,68)=12.55$, $p<0.001$ (see Fig. 1, middle and right bars). Thus, for non-medical scenarios (for both groups of participants), consistency was rated higher when another person had made the original decision, whereas, as reported above, in medical cases the resident participants rated consistency higher when the treating physician herself had made the original decision. This finding indicates that intra-individual consistency with past decisions is valued more by physicians evaluating medical decisions, while inter-individual consistency with past decisions is deemed more important in the other settings studied.

\section{Discussion}

The present experiment yielded several interesting findings concerning the reasoning of medical residents about hypothetical situations in which a person was portrayed as having to decide whether to persist with an original plan of action or switch to a more cost-effective alternative. First, the residents made fairly rational choices overall. They consistently rated the normative argument as the most attractive alternative while giving appropriately low ratings to both non-normative responses. Furthermore, their judgments when evaluating treatment options were not influenced by the amount of prior resources that had already been invested; that is, they did not demonstrate a sunk cost effect in evaluating medical treatment decisions. Second, they were more rational - in the sense of viewing switching to the more effective alternative as a relatively attractive option, while viewing continuing, the failed plan as relatively unattractive - when the decision involved choosing a course of medical treatment than when it involved everyday behaviors. Third, even though consistency was not a very attractive argument overall, the residents were more concerned about maintaining consistency with a previous medical treatment decision when that initial decision had been made by the present treating physician than when it had been made by someone else. However, they viewed consistency with a previous non-medical decision as more important when the initial decision had been made by someone else, a pattern that was also observed in the undergraduates' evaluations of non-medical decisions.

Although residents and undergraduates were similar in the weight they gave to the consistency rationale for continuing with a plan of action in non-medical situations, there were differences between the two groups of participants as well. Specifically, the undergraduates gave higher ratings to the non-normative responses (i.e., waste and consistency) than did the residents.

Although previous research has documented a number of cognitive biases in medical decision makers (e.g., Elstein et al., 1978; Dawson and Arkes, 1987; Hershberger et al., 1994), the present findings do not provide much additional support for the notion that physicians are poor reasoners. Most notably, residents' evaluations of treatment decisions were not influenced by the amount of time and/or money that had already been invested in treating a particular patient; in other words, they did not fall prey to the sunk cost effect when judging different treatment options. Despite the generally robust nature of the sunk cost effect in the psychological literature (Arkes and Blumer, 1985; Brockner, 1992; Bornstein and Chapman, 1994), resident participants' judgments about the optimal course of treatment were not influenced by previous treatment decisions. This encouraging finding supports other recent research indicating that biases in medical decision making may be more limited than previously thought (Christensen et al., 1995).

The resident participants did consider it more important for physicians faced with treatment decisions to appear consistent by continuing with a failed treatment plan when the physicians themselves had made the initial decision, compared to when another physician had made the initial decision. This finding supports previous research showing that. personal responsibility increases sunk cost behavior (Staw, 1976; Schoorman and Holahan, 1996) and that the desire to appear consistent - either to others or to oneself - is a powerful motive for behavior (Bobocel and Meyer, 1994); In deciding on medical treatments, physicians must consider not only what is rational — that is, the medically optimal strategy — but also what is socially desirable. Because inconsistency in medical treatment might be perceived as an implicit admission of error on the physician's part, it could lead to a host of undesirable social consequences, such as future litigation and loss of professional respect and opportunities. These 
effects would likely be even more salient in real situations, as opposed to the hypothetical decisions used in the present study.

Unfortunately, the residents' generally normative behavior in medical situations did not generalize to nonmedical settings. Although the medical and non-medical situations were not directly comparable, research on the sunk cost effect has found it to be very robust across a variety of situations (e.g., Arkes and Blumer, 1985; Larrick et al., 1990; Bornstein and Chapman, 1994). The medical and non-medical scenarios were analogous in the sense that both scenario types presented participants with situations in which an initial decision had proven unsuccessful, and a subsequent decision was then required either to continue with the original strategy or to switch to a more optimal alternative. In evaluating non-medical situations, residents rated sub-optimal responses higher (and the normative response lower) than when they were evaluating medical situations; furthermore, they demonstrated a sunk cost effect in judging everyday decisions. Although residents found the waste and consistency responses to everyday decisions less attractive than did undergraduates, they were nonetheless influenced by the amount of the original investment. In fact, undergraduates and residents were equally likely to be influenced by the size of a prior investment when reasoning about everyday situations; that is, there was no significant interaction between participant group and level of sunk cost. Thus, it appears that some aspect of residents' training may inoculate them against the sunk cost bias within the medical domain, but that they fail to apply this higher reasoning standard to the same degree in other settings.

Interestingly, consistency was viewed as a more attractive rationale for continuing the original plan in nonmedical scenarios (by both groups of participants) when someone else had made the initial decision than when the same decision maker had. This reversal provides evidence that physicians reason differently within their domain of expertise than outside it. Although some evidence exists suggesting that training in reasoning can transfer across situations (Nisbett et al., 1987; Larrick et al., 1990), the present results support the more common finding that the benefits of expertise are domain specific (Ericsson and Smith, 1991).

We can only speculate as to how medical training might serve to prevent the sunk cost effect in making medical decisions. Residents probably are not following an abstract principle about ignoring sunk cost; for if they were, they would show equivalent reasoning in the medical and non-medical scenarios. It also seems unlikely that residents are following an explicit domain-specific rule about ignoring sunk costs. Instead, they may be following domain-specific rules about which aspects of the situation to attend to. Decision principles that emphasize control- ling the quality of care, like "Pick the most effective treatment" or "Maximize the patient's outcome," would result in no sunk cost effect even though these principles do not explicitly mention sunk costs. However, because these principles are medicine-specific, they would be less likely to be applied to everyday decisions. The current study did not query residents as to the reasons or principles behind their decisions (except by asking them to rate their agreement with the three arguments provided). Future research needs to question physicians in a more open-ended manner as they actually engage in treatment decisions.

In conclusion, the present study yielded three major findings: First, residents did not exhibit a sunk cost effect in evaluating treatment decisions; that is, their evaluation of different courses of treatment was not affected by how much time or money had been invested in the initial treatment regimen. Second, the residents' reasoning about medical situations appeared to reflect a sense that physicians should be consistent in their patient management decisions. This desire for consistency might reflect a belief that changing treatments would be perceived as an admission of error . Third, this relatively normative reasoning on the part of the residents did not generalize to their non-medical decisions, in which their judgments - like those of undergraduates — did demonstrate a sunk cost effect. Thus, any advantage conferred by medical training in avoiding the sunk cost effect is limited to the medical domain. Overall, the present findings offer both good news and bad news: The good news is that doctors are not influenced by sunk costs in evaluating medical treatment decisions. The bad news is that this capacity for optimal reasoning does not generalize to non-medical situations.

\section{Appendix A. Sample scenarios}

Both of the following scenarios are in the same original decision maker-low sunk cost condition. Alternate .conditions (i.e., other original decision maker and high sunk cost) are shown in parentheses.

\section{Non-medical type}

Agatha decides that she wants to take cello lessons (Agatha's husband decides to give Agatha a cello and cello lessons for her birthday). She (he) spends US\$100 (US\$1,000) on a beginner cello and an additional US\$40 (US\$200) on the first month (3 months) of cello lessons. After 1 month (3 months) of lessons, Agatha realizes that she no longer enjoys the cello and wants to stop taking lessons. That is, it is almost certain that if Agatha signs up for more lessons, she will not enjoy them and will never enjoy playing the cello. What should Agatha do? 


\section{Medical type}

Ms. S., a 54-year-old female with a history of heartburn, comes to Dr. Gordon's office. Ms. S. had an upper GI series done 6 weeks ago which showed that she had gastroesophageal reflux (Ms. S. states that 6 weeks earlier her daughter's doctor ordered an upper GI series on her which showed that she had gastroesophageal reflux). Dr. Gordon (her daughter's doctor) gave her a prescription for Stopcid, an antisecretory medicine, which she has to take twice a day and is associated with some drowsiness. She purchased a four-month supply for US\$40 (US\$400). Ms. S. has been taking the medicine for 2 months and returns to Dr. Gordon's office because she is still having heartburn symptoms and is tired all the time. What should Dr. Gordon do?

\section{References}

Arkes, H.R., Blumer, C., 1985. The psychology of sunk cost. Organizational Behavior and Human Decision Processes 35, 124-141.

Arkes, H.R., Wortmann, R.L., Saville, P.D., Harkness, A.R., 1981. Hindsight bias among physicians weighing the likelihood of diagnoses. Journal of Applied Psychology 66, 252-254.

Asch, D.A., Baron, J., Hershey, J.C., Kunreuther, H., Meszaros, J., Ritov, I., Spranca, M., 1994. Omission bias and pertussis vaccination. Medical Decision Making 14, 118-123.

Baron, J., 1994. Thinking and deciding, 2d ed. Cambridge University Press, Cambridge.

Bazerman, M.H., Beekun, R.I., Schoorman, F.D., 1982. Performance evaluation in dynamic context: The impact of a prior commitment to the ratee. Journal of Applied Psychology 67, 873-876.

Bobocel, D.R., Meyer, J.P., 1994. Escalating commitment to a failing course of action: Separating the roles of choice and justification. Journal of Applied Psychology 79, 360-363.

Bornstein, B.H., Chapman, G.B., 1994. Learning a lesson from sunk cost. Journal of Experimental Psychology: Applied 1, 251-269.

Brockner, J., 1992. The escalation of commitment to a failing course of action: toward theoretical progress. Academy of Management Review 17, 39-61.

Christensen, C., Heckerling, P., Mackesy-Amiti, M.E., Bernstein, L.M., Elstein, A.S., 1995. Pervasiveness of framing effects among physicians and medical students. Journal of Behavioral Decision Making 8, 169-180.

Dawson, N.V., Arkes, H.R., 1987. Systematic errors in medical decision making: Judgment limitations. Journal of General Intern Medicine 2, 183-187.

Dawson, N.V., Arkes, H.R., Siciliano, C., Blinkhorn, R., Lakshmanan, M., Petrelli, M., 1988. Hindsight bias: An impediment to accurate probability estimation in clinicopathologic conferences. Medical Decision Making 8, 259- 264.
Detmer; D.E., Fryback, D.G., Gassner, K., 1978. Heuristics and biases in medical decision making. Journal of Medical Education 53, 682-683.

Elstein, A.S., 1988. Cognitive processes in clinical inference and decision making. In: Turk, D., Salovey, P. (Eds.), Reasoning, inference, and judgment in clinical psychology. Free Press, New York, pp. 17-50.

Elstein, A.S., Shulman, L.S., Sprafka, S.A., 1978. Medical problem solving: An analysis of clinical reasoning. Harvard University Press, Cambridge, MA.

Ericsson, K.A., Smith, J. (Eds.), 1991. Toward a general theory of expertise. Cambridge University Press, Cambridge.

Frisch, D., 1993. Reasons for framing effects. Organizational Behavior and Human Decision Processes 54, 399-429.

Garland, H., 1990. Throwing good money after bad: The effect of sunk costs on the decision to escalate commitment to an ongoing project. Journal of Applied Psychology 75, 728-731.

Gruppen, L.D., Margolin, J., Wisdom, K., Grum, C.M., 1994. Outcome bias and cognitive dissonance in evaluating treatment decisions. Academic Medicine 69, s57-s59.

Hershberger, P.J., Part, H.M., Markert, R.J., Cohen, S.M., Finger, W.W., 1994. Development of a test of cognitive bias in medical decision making. Academic Medicine 69, 839-842.

Larrick, R.P., Morgan, J.N., Nisbett, R.E., 1990. Teaching the use of cost-benefit reasoning in everyday life. Psychological Science 6, 362-370.

Mazur, D.J., Hickam, D.H., 1990. Treatment preferences of patients and physicians: Influences of summary data when framing effects are controlled. Medical Decision Making 10, $2-5$.

McNeil, B.J., Pauker, S.C., Tversky, A., 1984. On the framing of medical decisions. In: Bell, D.E., Raiffa, H., Tversky, .A. (Eds.), Decision making. Cambridge University Press, Cambridge, pp. 562-568.

Nisbett, R.E., Fong, G.T., Lehman, D.R., Cheng, P.W., 1987. Teaching reasoning. Science 238, 625-631.

Patel, V.L., Groen, G.J., 1991. The general and specific nature of medical expertise: A critical look. In: Ericsson, K.A., Smith, J. (Eds.), Toward a general theory of expertise. Cambridge University Press, Cambridge, pp. 93-125.

Poses, R.M., Anthony, M., 1991. Availability, wishful thinking and physicians' diagnostic judgments for patients with suspected bacteremia. Medical Decision Making 11, 159-168.

Schoorman, F.D., Holahan, P.J., 1996. Psychological antecedents of escalation behavior: Effects of choice, responsibility and decision consequences. Journal of Applied Psychology 81, 786-794.

Staw, B.M., 1976. Knee-deep in the Big Muddy: A study of escalating commitment to a course of action. Organizational Behavior and Human Performance 16, 27--44.

Whyte, G., 1993. Escalating commitment in individual and group decision making: A prospect theory approach. Organizational Behavior and Human Decision Processes 54, 430-455. 